\title{
LATERALLY RESTRAINED STEEL PLATE WITH STIFFENERS FOR SEISMIC RETROFITTING OF CONCRETE COUPLING BEAMS
}

\author{
B. Cheng ${ }^{1}$, R.K.L. $\mathrm{Su}^{2 *}$, C. $\mathrm{Shi}^{3}$ and C.T. Yang ${ }^{3}$ \\ ${ }^{I}$ Associate Professor, Department of Civil \& Transportation Engineering, \\ Beijing University of Civil Engineering and Architecture, China \\ ${ }^{2}$ Associate Professor, Department of Civil Engineering, The University of Hong Kong, \\ Pokfulam Road, Hong Kong, China \\ ${ }^{3}$ Master Candidate, Department of Civil \&Transportation Engineering, \\ Beijing University of Civil Engineering and Architecture, China \\ *(Corresponding author: E-mail: klsu@hku.hk)
}

Received: 15 April 2015; Revised: 18 September 2015; Accepted: 7 October 2015

\begin{abstract}
Existing deep reinforced concrete (RC) coupling beams with low shear span ratios and conventionally reinforced shear stirrups tend to fail in a brittle manner with limited ductility and deformability under reversed cyclic loading. Previous studies have developed a new retrofitting method with an unstiffened laterally restrained steel plate (LRSP) for existing deep RC coupling beams. By utilizing the post-buckling loading capacity of steel plate, the deformability and energy dissipation of the retrofitted coupling beams were enhanced while maintaining flexural stiffness during an earthquake. However, the occurrence of early plate buckling usually results in reduced strength, stiffness and energy dissipation capacity accompanied by significant pinching. In this study, half-scale deep RC coupling beams rehabilitated by LRSP with stiffeners were tested. The results demonstrate that the type of bolt connection greatly influences the performance of retrofitted coupling beams. The additional stiffeners can prevent plate buckling and ensure that the steel plate has a wider yield area and hence higher energy dissipation.
\end{abstract}

Keywords: Deep coupling beams, seismic retrofitting, laterally restrained steel plate, stiffener, bolt connection

DOI: 10.18057/IJASC.2016.12.2.7

\section{INTRODUCTION}

The need to retrofit in earthquake prone regions may arise directly from the problems of aging infrastructure, recognition of the vulnerability of existing infrastructure, updates in seismic code requirements, or changes in building performance objectives. Coupled shear walls are very frequently incorporated into high rise buildings as a primary lateral resisting system. Coupled beams in coupled shear walls are very important structural components that provide the necessary lateral strength, stiffness and deformability for the whole building to resist extreme wind and earthquake loads. In past decades, the design of many concrete buildings such as in Hong Kong have not taken into account earthquake actions. Following the introduction of the new design codes, many existing coupling beams are found to be deficient in shear capacity. Paulay [1] has pointed out that deep reinforced concrete (RC) coupling beams are prone to brittle failure in the form of diagonal or sliding failure when insufficient shear reinforcement is used. Past earthquake records [2, 3] also reveal that many deep RC coupling beams have been seriously damaged in a typical shear failure mode during major earthquakes. Under strong earthquake loads, brittle failures of these coupling beams could significantly affect their energy dissipation ability and the structural safety of the entire building. To improve the seismic resistance of existing buildings, many coupling beams deficient in shear or lacking in deformability need to be retrofitted. 
Only a few studies in the literature are related to the seismic retrofitting of existing RC coupling beams. Harries et al. [4] studied a shear strengthening method for existing coupling beams with a span-to-depth ratio of 3.0. In their study, the retrofitting involved a number of different attachment methods to fix the steel plate to one side of the coupling beams. They found that the hybrid method of bolting and epoxy bonding to attach the steel plates both in the span and at the ends performed the best. Su and Zhu [5] studied a shear strengthening method for RC coupling beams with a span-to-depth ratio of 2.5. To strengthen the coupling beams, they bolted the steel plate to both ends of the wall panels without adhesive bonding. Their experimental studies showed that this retrofitting method could greatly increase the shear capacity of medium length coupling beams, while fastening the retrofit plate to the span of a concrete beam could prevent local buckling of the steel plates, but this led to serious concrete damage at the failure stage. In all experiments of $\mathrm{Su}$ and Zhu, minor buckling of the steel plate was observed and the effects of local buckling on the behavior of strengthened coupling beams were not investigated. The widths of door and window openings usually range from 1.0 to $1.5 \mathrm{~m}$, while height ranges from 1.5 to $2.5 \mathrm{~m}$; thus, many coupling beams above the openings are rather short and deep. Su and Cheng $[6,7]$ experimentally studied the use of a laterally restrained steel plate (LRSP) without stiffeners to retrofit deep concrete coupling beams with a span-to-depth ratio of 1.1. In the test, thin mild steel plates were utilized. The steel plate started to develop a diagonal tension field after the onset of global buckling at the early stages of loading and exhibited nonlinear behavior at relatively small inter-story drift ratios. Due to the post-buckling loading capacity and tension field action in the steel plate, LRSP retrofitted coupling beams failed in a ductile manner. Cheng and $\mathrm{Su}$ [8] conducted a numerical parametric study to investigate the influence of plate buckling on the LRSP retrofitted coupling beams. However, shear buckling of steel plate in the early stages usually results in reduced strength, stiffness and energy dissipation capacity accompanied by significant pinching. $\mathrm{Lu}$ and $\mathrm{Li}$ [9] proposed slim buckling-restrained steel plate shear walls to seismically strengthen the lateral load resistance of buildings. The stable hysteresis curve, good deformability, and high energy dissipating ability of the proposed buckling-restrained steel plate shear wall were demonstrated experimentally. In this study, we attempt to add steel stiffeners to the steel plate to defer the shear buckling and to increase the energy dissipation capacity of the retrofitted beams. A series of LRSPs with stiffeners have been tested to investigate the effectiveness of the proposed method in the prevention of pinching of the hysteresis curves and increasing the energy dissipation capacity of the retrofitted coupling beams.

\section{LRSP RETROFITTING METHOD}

The main characteristic of the LRSP retrofitting method is the use of a plate buckling control device, which is composed of steel angles (Figure 1). Cheng and Su [7] applied the plate buckling control device to effectively suppress laterally out-of-plane plate buckling. To avoid adding extra flexural strength and stiffness to the retrofitted coupling beam, the lateral stiffeners are connected to a steel plate by bolt connections with slotted holes, which allow the two lateral stiffeners to freely rotate and move in the longitudinal direction. The advantage of using a plate buckling restraining device instead of adding stiffeners to the steel plates to control plate buckling is that the stiffness of the coupling beams would not be increased. This is important because the increase in the beam's stiffness would stiffen the lateral load resisting system and cause the structure to attract more seismic loads, which might lead to early failure of the coupled shear walls under strong seismic loads. Experimental studies have demonstrated that, for the specimens with the buckling control device, plate buckling at the beam-wall joints is suppressed. A continuous shear transfer medium across the joints, provided by the steel plate, can continue to take a larger share of the load in the post peak region and alleviate concrete crushing in the compression region. As a result, LRSP retrofitted coupling beams failed in a more ductile fashion. 


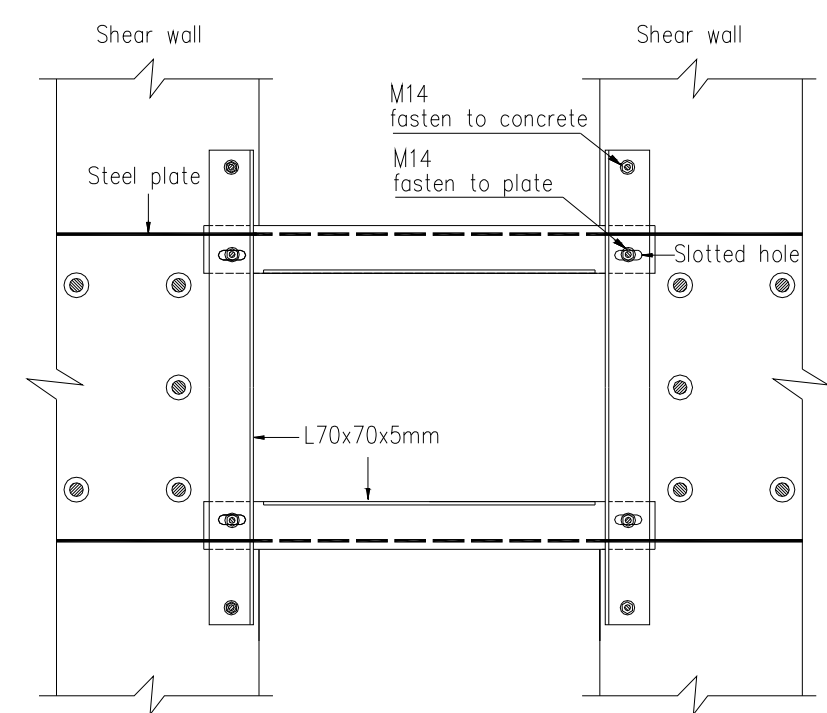

Figure 1. LRSP Retrofitting Method

\section{EXPERIMENTAL PROCEDURE}

\subsection{Description of Test Specimens}

Five specimens with the same dimensions and reinforcement specifications (see Figure 2a), but different retrofitting schemes, were fabricated and tested. Each beam was connected to two RC panels, simulating a section of the coupled shear walls, to properly model the beam-wall interactions. Two base beams were attached to the top and bottom ends of each specimen and rotated $90^{\circ}$ to fix the specimen onto the loading frame via anchor-bolt connections.

The sizes of the coupling beams were $450 \mathrm{~mm}$ deep by $120 \mathrm{~mm}$ wide, with a clear span of $500 \mathrm{~mm}$ and a span-to-depth ratio of 1.11. The top and bottom longitudinal reinforcements of the coupling beams consisted of four $12 \mathrm{~mm}$ diameter high-yield reinforcement bars with a steel ratio of $0.8 \%$, and the side bars included four $8 \mathrm{~mm}$ diameter mild steel round bars. The shear reinforcements in the coupling beams consisted of four $8 \mathrm{~mm}$ diameter hoops with a $125 \mathrm{~mm}$ pitch. This shear reinforcement arrangement was selected to represent the shear-deficient coupling beams in old existing buildings.

Given the limited load capacity of a $500 \mathrm{kN}$ hydraulic jack, the original coupling beam DCB8 was designed to achieve a loading of less than $50 \%$ of the jack capacity, according to the provisions given in the old British Standard CP114 [10], meaning that the jack was able to cause the retrofitted coupling beams to fail. For the specimens with a bolted steel plate, the capacity of the steel plates should not be higher than $250 \mathrm{kN}$. The shear capacity of steel plates was designed according to the British Standard BS5950 [11] with a full plastic assumption, which ignored the effects of steel plate buckling and bolt group slippage. The material properties of concrete, steel and rebar are shown in Table 1. Through the design calculation, thin steel plates of $4.5 \mathrm{~mm}$ were selected. 

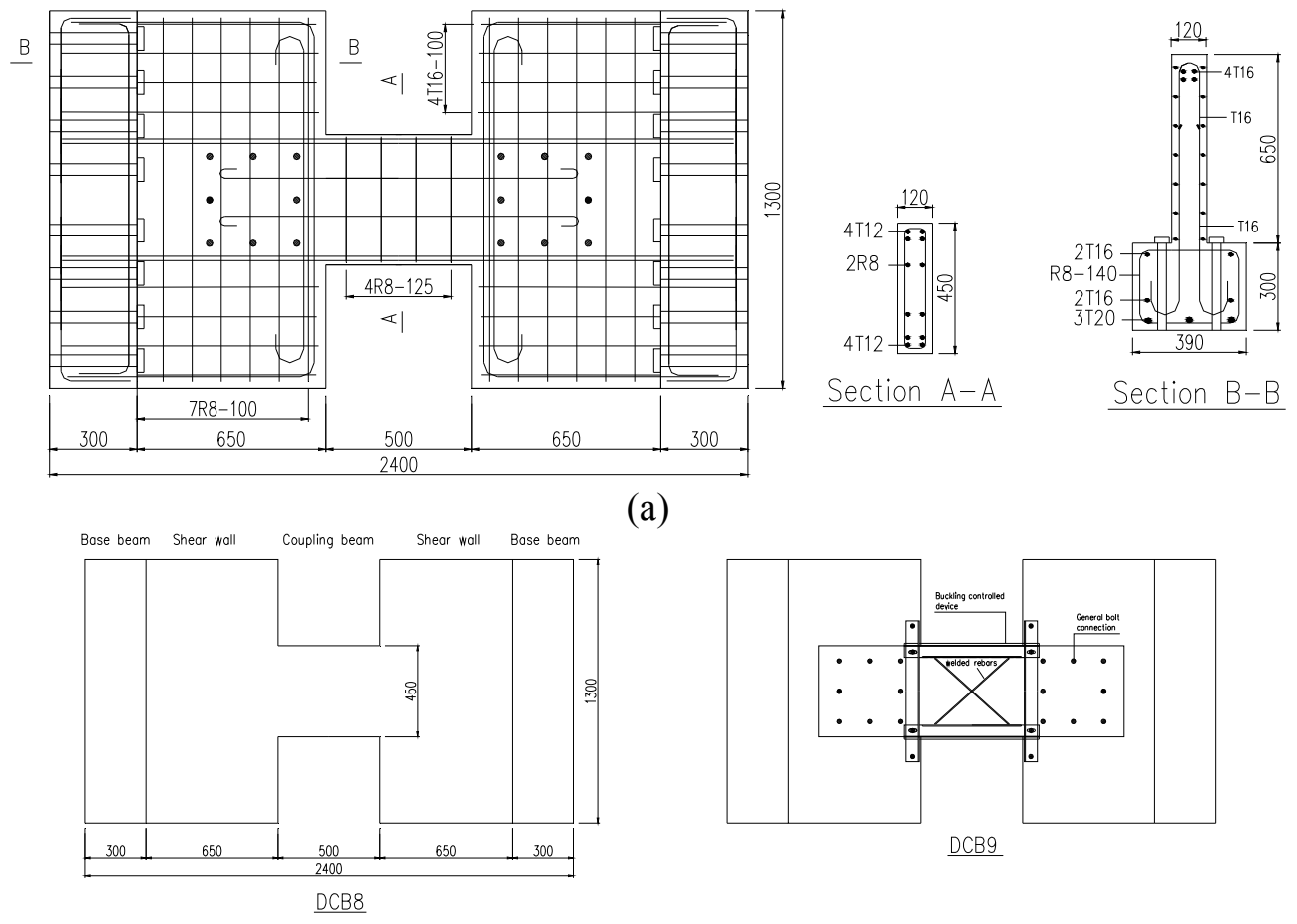

(a)
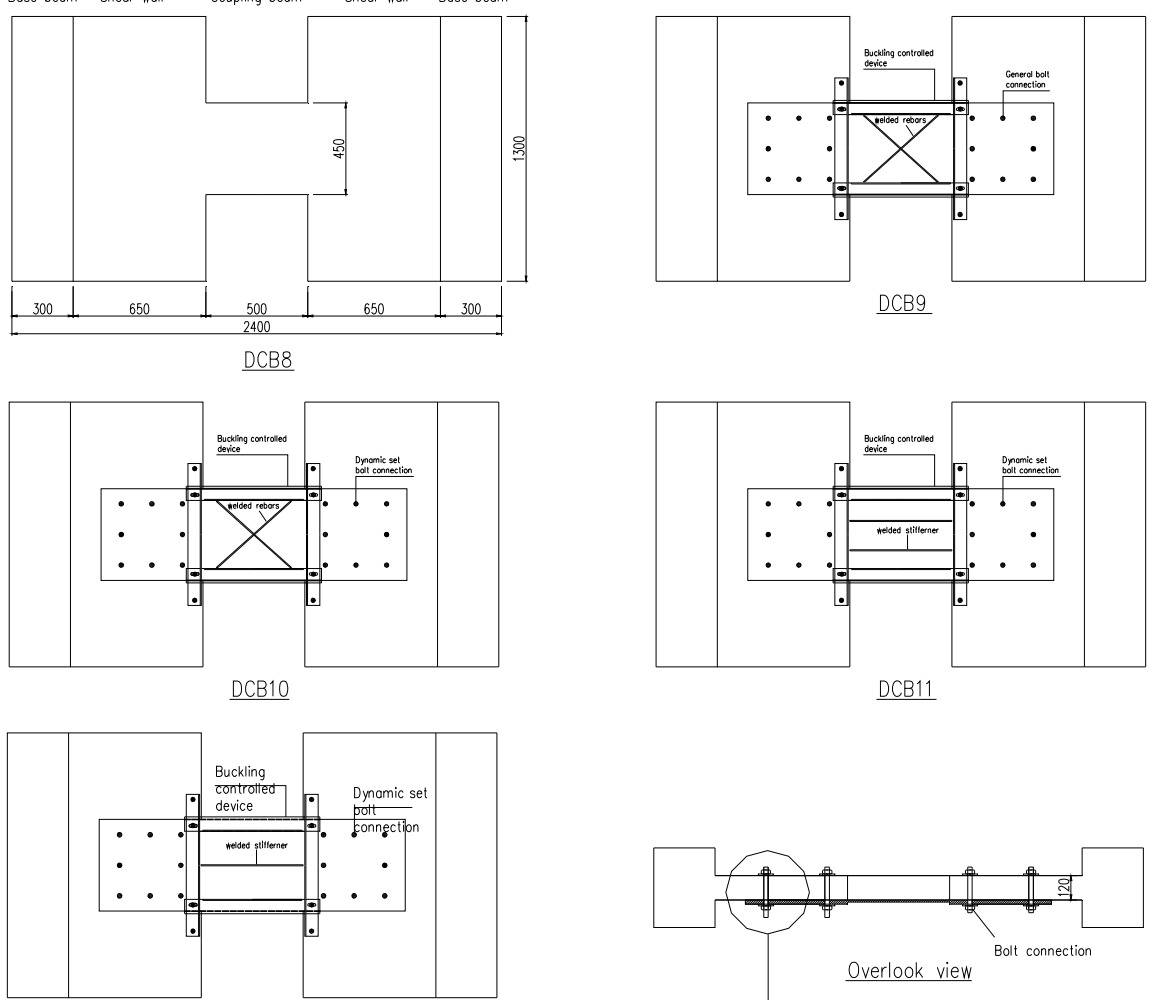

$\underline{\mathrm{DCB} 12}$
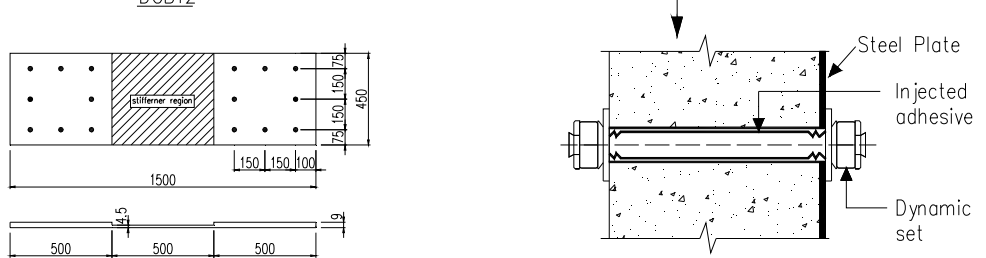

Steel plate

Dynamic set bolt connection

(b)

Figure 2. Details of test specimens: (a) RC details and (b) bolt-plate configurations 
Table 1. Material Properties

\begin{tabular}{cc|cc}
\hline & Concrete & \multicolumn{2}{c}{ Steel plate } \\
\hline Specimen & $f_{c u}(\mathrm{MPa})$ & $f_{y p}(\mathrm{MPa})$ & $\mathrm{E}$ \\
& & & \\
DCB8 & 59.6 & 362 & 203,420 \\
DCB9 & 61.4 & 367 & 203,536 \\
DCB10 & 60.3 & 345 & 200,386 \\
DCB11 & 60.1 & 353 & 200,652 \\
DCB12 & 62.6 & \\
\hline \multicolumn{3}{c}{$E(\mathrm{MPa})$} \\
\hline Type & Reinforcement bars \\
T12 & $f_{y}(\mathrm{MPa})$ & 199,300 \\
T16 & 545 & 187,865 \\
T20 & 556 & 195,643 \\
R8 & 484 & 189,500 \\
\hline
\end{tabular}

The retrofitting schemes of all the specimens are shown in Table 2 and Figure $2 \mathrm{~b}$. The first specimen DCB8 with a plain RC arrangement was used for control purposes. The LRSP method and stiffeners were all applied to Specimens DCB9 to DCB12, as shown in Figure 2b. Stiffeners are structural elements connected to the steel sheet by continuous fillet welds. Rigid stiffeners are used to ensure that the plate can reach its full plastic strength and avoid overall buckling. Through numerical studies of the local buckling effects of steel plate, Cheng and Su [8] numerically found that, for steel plate with span-to-depth ratio 1.1, the height to thickness $(h / t)$ ratio of steel plate should be lower than 62.5. Therefore, one horizontal or two horizontal and diagonal stiffeners are adopted. Rectangular steel plates with width of $20 \mathrm{~mm}$ and thickness of $9 \mathrm{~mm}$ are selected as horizontal stiffeners and steel rebars with diameter of $10 \mathrm{~mm}$ are selected as diagonal stiffeners The stiffeners are placed symmetrically along the span of the steel plate, as shown in Figure 3.

Table 2. Coupling Beam Details

\begin{tabular}{|c|c|c|c|c|c|c|}
\hline $\begin{array}{c}\text { Specime } \\
\mathrm{n}\end{array}$ & Stiffeners & $\begin{array}{c}\text { Plate } \\
\text { thickness } \\
\text { at span }\end{array}$ & $\begin{array}{c}\text { Plate } \\
\text { thickness } \\
\text { at ends }\end{array}$ & $\begin{array}{l}\text { LRSP } \\
\text { method }\end{array}$ & $\begin{array}{c}\text { Bolt } \\
\text { property }\end{array}$ & $\begin{array}{l}\text { Type of bolt } \\
\text { connection }\end{array}$ \\
\hline DCB8 & N/A & N/A & N/A & N/A & N/A & N/A \\
\hline DCB9 & $\begin{array}{c}\text { Two } \\
\text { diagonal }\end{array}$ & $4.5 \mathrm{~mm}$ & $9 \mathrm{~mm}$ & Added & $\begin{array}{c}\text { High-tensile } \\
\text { steel }\end{array}$ & General \\
\hline DCB10 & $\begin{array}{c}\text { Two } \\
\text { diagonal }\end{array}$ & $4.5 \mathrm{~mm}$ & $9 \mathrm{~mm}$ & Added & $\begin{array}{l}\text { High-tensile } \\
\text { steel }\end{array}$ & Dynamic set \\
\hline DCB11 & $\begin{array}{c}\text { Two } \\
\text { horizontal }\end{array}$ & $4.5 \mathrm{~mm}$ & $9 \mathrm{~mm}$ & Added & $\begin{array}{l}\text { High-tensile } \\
\text { steel }\end{array}$ & Dynamic set \\
\hline DCB12 & $\begin{array}{c}\text { One } \\
\text { horizontal }\end{array}$ & $4.5 \mathrm{~mm}$ & $9 \mathrm{~mm}$ & Added & $\begin{array}{c}\text { High-tensile } \\
\text { steel }\end{array}$ & Dynamic set \\
\hline
\end{tabular}

The anchors at the ends of the steel plates were designed to be strong enough to transfer all loading from the steel plates to the wall regions using the linear bolt group theory. To avoid plate buckling in the anchor regions, thicker steel plates of $9 \mathrm{~mm}$ (which is twice the thickness of the plate in the span) were used in the anchor regions. To allow for construction tolerances, clearance through-holes were provided in the steel plates and concrete walls. 


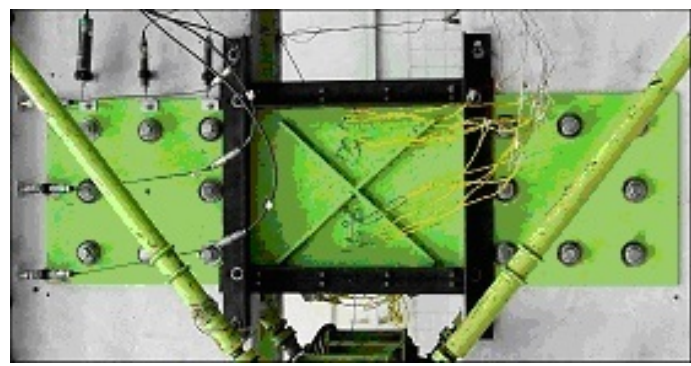

DCB9

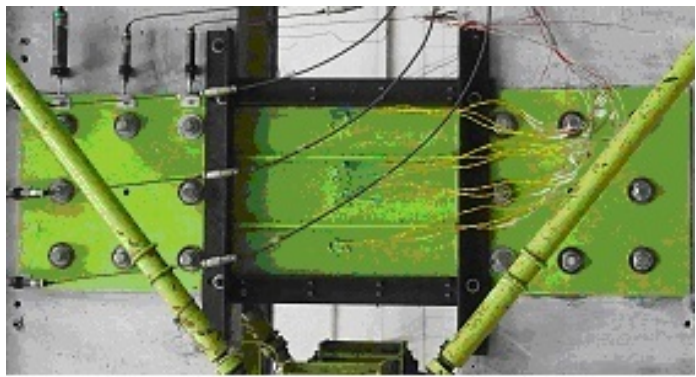

DCB11

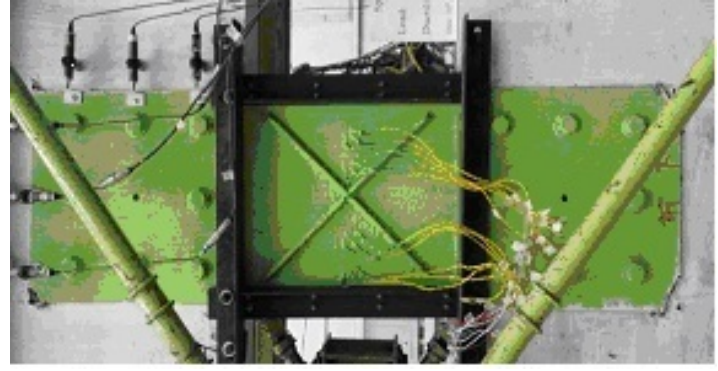

DCB10

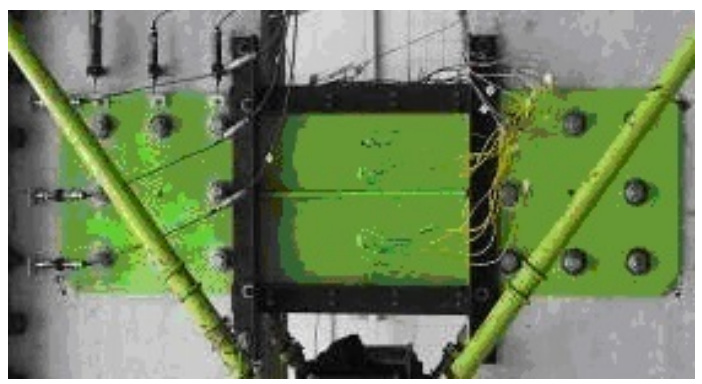

$\mathrm{DCB} 12$

Figure 3. Stiffeners on Steel Plate

Since the steel plates were attached to coupling beams solely by bolt connections, the strength, stiffness and fixing details of the bolts would significantly influence the behavior of the entire retrofitting system. In this study, $20 \mathrm{~mm}$ diameter high strength bolts were used to fix the external steel plate, while slightly larger clearance through $22 \mathrm{~mm}$ diameter holes was provided in the steel plates and concrete walls to allow for fabrication tolerances. Two types of bolt connection are adopted in the specimens. One is the general bolt connection which screws the bolts by tightening torque to about $0.3 \mathrm{kNm}$ (according to China Standard Q/STB 12.521.5-2000). The other is the dynamic set bolt connection which minimizes any possible slippage between various components at the connections by injecting adhesive to fill the gaps between the bolt shank and surrounding concrete (see Figure 2b).

\subsection{Test Setup, Loading Procedure and Instrumentation}

The load frame shown in Figure 4, designed by Kwan and Zhao [12], was used in the tests. To facilitate loading, the specimens were rotated $90^{\circ}$ from their actual positions. The bottom end of each specimen was attached to a horizontal steel beam that was fixed to the floor, while the top end was attached to a structural steel beam that could move horizontally during the loading process. Reversed cyclic loading was applied by a $500 \mathrm{kN}$ servo-controlled hydraulic actuator through a rigid arm at the top end of the specimen where the line of action of the applied shear force passed through the center of the beam. In this way, the coupling beam was loaded with a constant shear force along the span and a linearly varying bending moment with the point of inflection located at the mid-span, which simulated the real situation.

The specimens were tested under reversed cyclic loading to simulate an earthquake or wind forces. The loading process was divided into two phases: the first phase was load-controlled and the second phase was displacement-controlled. Reversed cyclical loading was applied to each specimen up to $75 \%$ of the estimated ultimate shear capacity $\left(V_{u}^{*}\right)$. The subsequent cycles were displacement-controlled, in which the specimen was displaced to a nominal ductility factor $\left(\mu_{n}=1\right)$ 
for one cycle and then to each successive nominal ductility factor for two cycles, as illustrated in Figure 5 . The beam rotations $(\theta)$, defined as the differential displacement between the two beam ends $(\Delta)$ in the loading direction divided by the clear span $(l)$, were calculated using the displacements measured by the linear variable displacement transducers (LVDTs) L3 and L4, as illustrated in Figure 5. The nominal yield rotation $\left(\theta_{y n}\right)$ at $\mu_{n}=1$ originated from Park [13] and is obtained by extrapolating the average of the $\theta$ values corresponding to the positive and negative loads at $0.75 V_{u}^{*}$ in the first cycle by a factor $4 / 3$. The actual yield rotation $\left(\theta_{y}\right)$ was obtained in the same manner from the maximum measured shear $\left(V_{\mathrm{u}}\right)$. The test was terminated when the peak load reached in the first cycle of a nominal ductility level fell below the lesser of $0.8 V_{u}^{*}$ and $0.8 V_{\mathrm{u}}$ and the test specimen failed.

\section{Coupling Beam Test Setup}

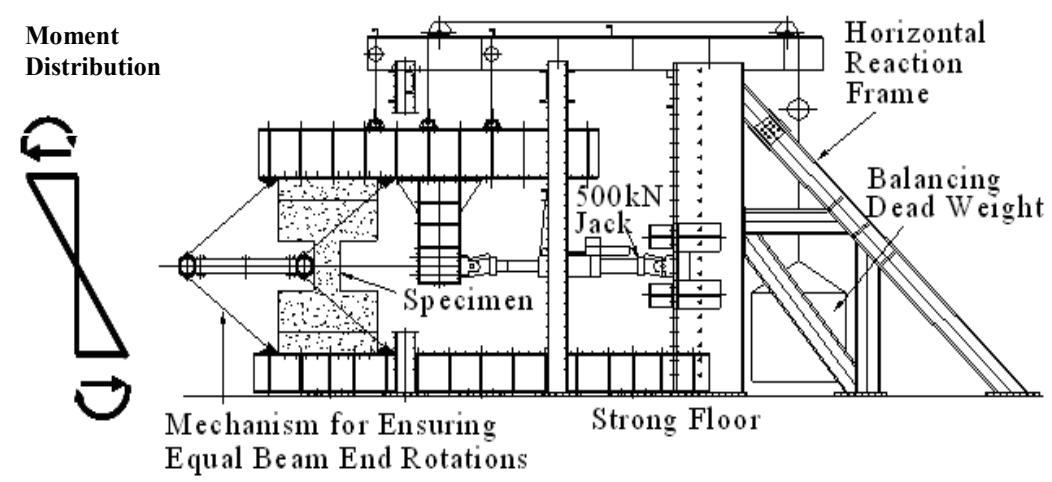

Figure 4. Test Setup

A number of instruments, including Linear Variable Displacement Transducers (LVDTs) and strain gauges, were installed to capture the deflection, curvature profiles and slippage of the bolt group in the anchor region. Strain gauges were attached along the plates, longitudinal bars and stirrups to investigate the deformations and internal load distributions of the steel plates and steel bars. The arrangements of the LVDTs and strain gauges are shown in Figures 6(a) and 6(b), respectively.

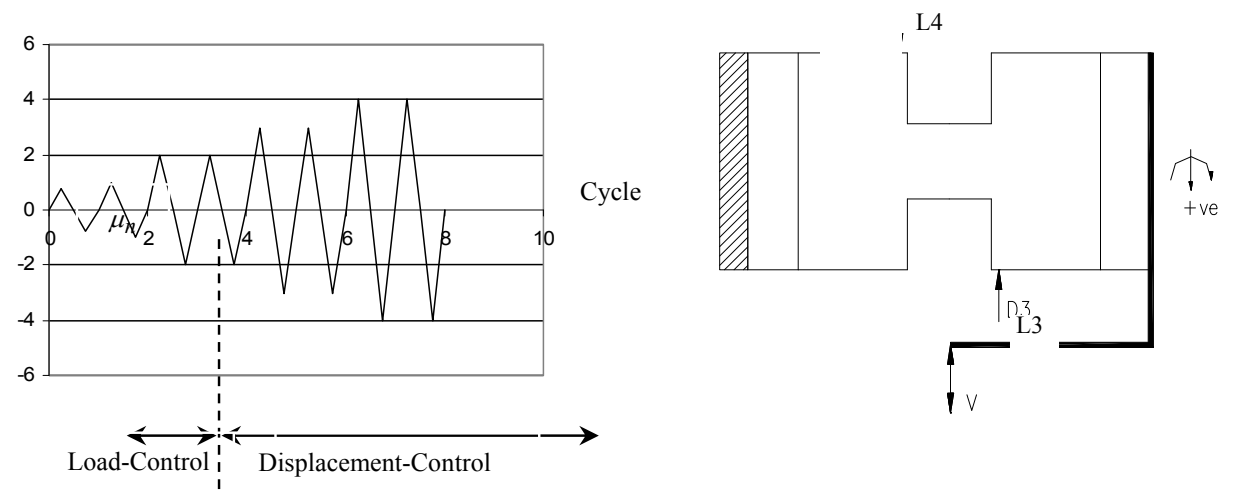

Figure 5. Loading History 


\section{RESULTS AND DISCUSSION}

\subsection{Strength, Deformation and Ductility}

The performance of the specimens was evaluated through the measured strains and LVDT data. Several parameters were defined to interpret the results of the tests. The ultimate rotation $\theta_{u}$ is defined as the chord rotation angle at $0.8 V_{\mathrm{u}}$ of an envelope curve on the softening branch and the yield chord rotation $\theta_{y}$ is defined as the chord rotation angle at $0.75 V_{\mathrm{u}}$ of an envelope curve on the increasing branch. The maximum ductility $\mu$ is equal to the ultimate rotation $\theta_{u}$ divided by the yield chord rotation $\theta_{y}$. As the test values for the positive cycles were not the same as those for the negative cycles, the values from the positive and negative cycles were averaged. It should be noted that Table 3 gives a summary of the experimental results before the rotation of $0.04 \mathrm{rad}$. This is because Qian and Xu [14] studied the deformation decomposition rule of RC shear wall structures and established the relationship between the deformation of coupling beams and inter-story drift. They pointed out that the rotation of coupling beam is about twice of the inter-story drift. Furthermore, Chinese Code (GB50011-2010) gives the inter-story drift ratio limit of 0.01 rad for high rise shear wall buildings under major earthquake conditions. Therefore if the rotation demand of coupling beams is more than $0.04 \mathrm{rad}$, the inter-story drift ratio demand of high rise shear wall buildings would probably exceed the codified drift limit.

Table 4 summarizes the experimental results of the ultimate strength $V_{\mathrm{u}}$, the ultimate rotations $\theta_{u}$ and the ductility $\mu$ of all the tested beams. By comparing the test results of the retrofitted beams with those of the control specimen (DCB8), the increases in strength, rotation and ductility were calculated. By comparing the test results of DCB9 with general bolt connections and those of DCB10 with dynamic set bolt connections, the effects of bolt connections is revealed. It can be seen that the shear strengths $V_{\mathrm{u}}$ and ultimate rotation $\theta_{u}$ of DCB9 were all decreased when compared with those of the controlled specimen while the shear strengths $V_{\mathrm{u}}$ and ultimate rotation $\theta_{u}$ of DCB10 were increased by $67 \%$ and $116 \%$, respectively. The results indicate that the type of bolt connection has significant effects on the behavior of retrofitted coupling beams. General bolt connections with clearance holes on steel plates result in large bolt slippage at the early loading stage. As a result, the concrete and steel plate did not work together effectively. Meanwhile, the dynamic bolt connections, with injected adhesive to fill the gap between the clearance hole and bolt shank, alleviated the slippage and ensured that the plate and concrete moved together effectively.

Table 3. Summary of Experimental Results

\begin{tabular}{|c|c|c|c|c|c|c|c|c|c|c|c|}
\hline Specimen & $\begin{array}{r}\text { Failure } \\
\text { Mode }\end{array}$ & $\begin{array}{l}V_{u}^{*} \\
\mathrm{kN}\end{array}$ & $\begin{array}{c}V_{u} \\
\mathrm{kN}\end{array}$ & $\begin{array}{c}V_{u} \\
\text { increased } \\
\%\end{array}$ & $\begin{array}{c}v_{\max } \\
\mathrm{MP} \\
\mathrm{a}\end{array}$ & $\begin{array}{l}\theta_{y} \\
\mathrm{rad}\end{array}$ & $\begin{array}{c}\theta_{u} \\
\mathrm{rad}\end{array}$ & $\begin{array}{c}\theta_{u} \\
\text { increased } \\
\%\end{array}$ & $\mu$ & $\begin{array}{c}\mu \\
\text { increased } \\
\%\end{array}$ & $\begin{array}{c}K_{\mathrm{o}} \\
10^{6} \mathrm{kN} / \mathrm{m} \\
\mathrm{m}\end{array}$ \\
\hline DCB8 & brittle & 242 & 246 & $\mathrm{~N} / \mathrm{A}$ & 4.6 & $\begin{array}{c}0.005 \\
5\end{array}$ & $\begin{array}{c}0.018 \\
6\end{array}$ & N/A & 3.4 & N/A & 27 \\
\hline DCB9 & brittle & 460 & 244 & N/A & 5.4 & $\begin{array}{c}0.003 \\
9\end{array}$ & $\begin{array}{c}0.015 \\
2\end{array}$ & -18 & 3.9 & 15 & 38 \\
\hline DCB 10 & ductile & 460 & 411 & 67 & 7.6 & $\begin{array}{c}0.009 \\
2\end{array}$ & $\begin{array}{c}0.040 \\
3\end{array}$ & 116 & 4.4 & 29 & 27 \\
\hline DCB11 & brittle & 460 & 400 & 63 & 7.4 & $\begin{array}{c}0.008 \\
3\end{array}$ & $\begin{array}{c}0.028 \\
7\end{array}$ & 54 & 3.5 & 3 & 29 \\
\hline DCB 12 & ductile & 460 & 366 & 49 & 6.8 & $\begin{array}{c}0.007 \\
6\end{array}$ & $\begin{array}{c}0.037 \\
4\end{array}$ & 101 & 4.9 & 44 & 29 \\
\hline
\end{tabular}

By comparing the results of DCB11 with DCB12, the effects of the number of stiffeners can be studied. The only difference between these two specimens is the number of stiffeners used, DCB11 
using two horizontal stiffeners and DCB12 using only one horizontal stiffener. The shear strengths $V_{u}$ and ultimate rotation $\theta_{u}$ of DCB11 were increased by $63 \%$ and $54 \%$, respectively, while the shear strengths $V_{u}$ and ultimate rotations $\theta_{u}$ of DCB12 were increased by $49 \%$ and $101 \%$, respectively. The results reveal that the number of stiffeners has significant effects on the behavior of retrofitted coupling beams. By adding fewer stiffeners, the increase in rotation deformability is much higher than the increase in shear strength. This is because using more stiffeners makes the plate more rigid and less ductile.

By comparing the results of DCB10 and DCB11, the effects of the stiffener arrangement can be investigated. The only difference between these two specimens is the arrangement of stiffeners, two diagonal stiffeners for DCB10 and two horizontal stiffeners for DCB11. The shear strength $V u$ and ultimate rotation $\theta_{u}$ of DCB10 were increased by $67 \%$ and $116 \%$, respectively, while the shear strength $V_{u}$ and ultimate rotation $\theta_{u}$ of DCB 11 were increased by $63 \%$ and $54 \%$, respectively. These results show that the stiffener arrangement can affect the deformability but not the shear capacity of the retrofitted beams. Diagonally arranged stiffeners can increase the deformability much more than horizontally arranged stiffeners for the retrofitted coupling beams.

The theoretical shear capacity $\left(V_{\text {code }}{ }^{*}\right)$ of DCB8, determined according to British Standards, is 242 $\mathrm{kN}$ which is very close to the average shear capacity $(246 \mathrm{kN})$ obtained from the experiment. However, the theoretical shear capacities $\left(V_{\text {code }}{ }^{*}\right)$, using the full plastic assumption for steel plate of the retrofitted specimens, is $460 \mathrm{kN}$. Significant errors can occur in the prediction of shear capacity as a result of ignoring bolt slippage. For DCB9, with the general bolt connections, large bolt slippage can cause significant error (46\%) in shear strength prediction. Meanwhile, for DCB10 and DCB12 with dynamic bolt connections, this error can be reduced to $10 \%$ to $25 \%$.

The initial stiffness $K_{0}$ was obtained by dividing the load at $75 \%$ of the ultimate load by the corresponding displacement. As shown in Table 4, the initial stiffnesses $K_{0}$ of the retrofitted coupling beams are almost the same as those of the original specimen DCB8, but not those of specimen DCB9. The reason is that, for DCB9, with general bolt connections, at the early loading stage, concrete beam solely resists the shear loading, resulting in a lesser yield rotation than that of the other specimens. It can be concluded from the test results that this new seismic retrofitting method can increase the deformation and ductility of deep RC coupling beams while avoiding any substantial increase in their flexural stiffness. Since the total amount of base shear induced in a building during an earthquake is primarily dependent on the lateral stiffness of the structure, the proposed method would not impose extra forces on the building after seismic retrofitting.

\subsection{Crack Patterns and Failure Behaviors}

The concrete crack patterns of the test specimens were all very similar. The first cracks in the test specimens all occurred at the beam-wall joints and were inclined at about $45^{\circ}$. As the applied load increased, major diagonal cracks were formed across the beam span. These extensive diagonal cracks indicate that the shear capacity of the beams was insufficient. This result agrees with the anticipated brittle shear failure mode as a sufficient amount of longitudinal steel has been provided to avoid flexural failure prior to shear failure. The wall piers, including the joint regions, only experienced slight cracks when the beams failed.

Figure 7 shows the crack patterns of the control specimen DCB8 and the retrofitted specimens DCB9 and DCB10 at the same load level of $200 \mathrm{kN}$. It can be seen that serious diagonal cracks appeared in DCB8 and DCB9 at the early loading stage. Meanwhile, for DCB10, with dynamic bolt connections, at the same load level, much smaller diagonal cracks were observed. This means that the LRSP works well with the concrete beam from the early loading stage. This can help to delay 
the increase in width of the diagonal cracks in concrete.

From the strain gauge data in the shear stirrups, the applied load corresponding to yielding of the stirrups can be identified. For the control specimen DCB8, the shear stirrups started to yield when the load increased to $264 \mathrm{kN}$. Soon after yielding, the shear force could no longer be resisted and the specimen reached its peak capacity (also at $264 \mathrm{kN}$ ). The results indicate that insufficient shear reinforcement is the primary cause of failure for the control specimen. When the shear links yielded, the strength could not be increased much further and shear link yielding caused the crack width to increase at a faster rate. The presence of high transverse tensile strains in the diagonal compressive struts eventually led to concrete cracking and crushing. For DCB9, the shear stirrups also yielded at a load of about $260 \mathrm{kN}$ which is very similar to the case of DCB8. This means that, with the adoption of the general bolt connections, the additional steel plate did not mobilize initially and the shear transfer across the beam-wall joints through the steel plate was not activated. Hence, both DCB8 and DCB9 experienced a brittle failure mode. For DCB10 to DCB12, the shear stirrups also yielded at their ultimate load (at around $400 \mathrm{kN}$ ). The results show that, with the adoption of dynamic set bolt connections, the concrete beam can effectively work with the additional steel plate, and the steel plate contributes to the shear resistance in the early loading stage. Therefore, the shear links yielded at a higher load level and the crack width increased at a slower rate. This can also explain why Specimens DCB10 to DCB12 have better deformability.

\subsection{Load-rotation Curves}

Figure 8 shows the load-chord rotation hysteresis loops for all the specimens. The load-rotation curve of the control specimen DCB8 exhibited substantial pinching after reaching the peak load. This pinching is associated with a rapid stiffness degradation and reduced energy dissipation in the post-peak regime. For DCB9, due to the significant bolt slips, the steel plate did not deform in the early rotation level $(<0.04 \mathrm{rad})$. The load-rotation curve of DCB9 is very similar to that of DCB8, while in the later rotation level $(>0.04 \mathrm{rad})$, the load-rotation curve is similar to that seen with steel plate only. For DCB10 to DCB12, it can be seen that the pinching was less serious. Comparing the envelopes of the load-rotation curves, the retrofitted specimens (DCB10 to DCB12) with restrained plates exhibited more ductile behavior after the peak loads.

Compared with the previous beam test results [7] using LRSP without stiffeners, we have found that stiffeners can reduce the pinching effect, resulting in a more stable hysteresis behavior and higher energy dissipation. However, using stiffeners cannot completely mitigate the pinching effect.

\subsection{Energy Dissipation and Stiffness Degradation}

In order to compare the energy dissipation of the specimens, the energy dissipation coefficient ( $w$ ) in each half-cycle was evaluated. The value of $w$ is a ratio of the energy dissipation in each half-cycle to the elastic potential energy at the largest amplitude. Figure 9 shows the variations in $w$ with a nominal ductility level in the first cycles. During the early ductility levels, the energy dissipation coefficients of all the specimens were small. At this stage, only hair cracks were observed and specimens remained elastic, which resulted in the small energy dissipation. For DCB8 and DCB9, the energy dissipation coefficients increased rapidly at the ductility level $\left(\mu_{n}= \pm 1\right)$. This is because, at this stage, major diagonal cracks occurred in the specimens and large energy dissipation suddenly occurred. With the increase in ductility demands, the energy dissipation coefficients of DCB8 and DCB9 decreased rapidly. This is because brittle shear failure occurred. For DCB10 to DCB12, the energy dissipation coefficients increased after the ductility level $\left(\mu_{n}= \pm 1\right)$; this means that the specimens entered into the inelastic deformation region later than the control specimen DCB8 and DCB9 with general bolt connections. With the increase in ductility 
demand, the energy dissipation coefficients of the specimens remain stable and have an increasing trend. This is due to good composite action between the concrete beam and the steel plate, which has a stable shear deformation.

Figure 10 shows the variations $r_{\mathrm{k}}$, which is a ratio of the secant stiffness $(K)$ in the first cycle to that in the former first cycle at each nominal ductility level. Differences among the specimens were generally insignificant. It can be seen that, in the early ductility level $\left(\mu_{n}= \pm 0.5\right)$, the secant stiffness of DCB8 was lower than that of the retrofitted coupling beams (DCB10 to DCB12). All specimens exhibited a severe loss of stiffness with the increase in deformation due to the occurrence of diagonal shear cracking in the concrete. It can be seen that, in DCB8 and DCB9, the stiffness decreased more rapidly than in the other specimens. For DCB10 to DCB12, although the additional steel plates have different stiffener arrangements, the variations of secant stiffness are very similar throughout the whole loading process.

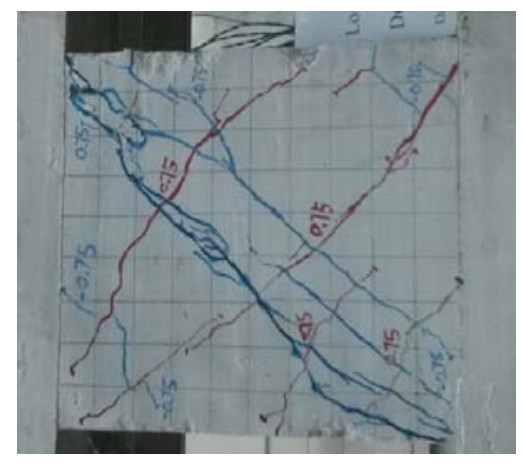

DCB8

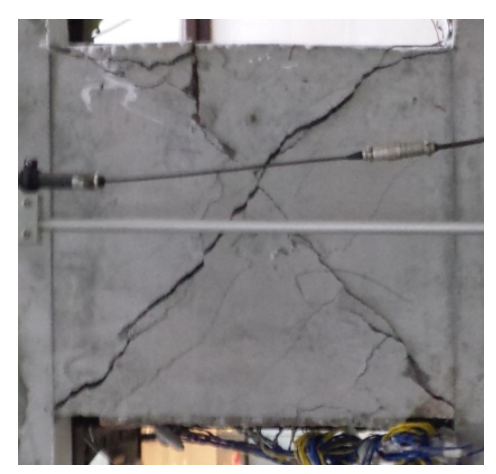

DCB9

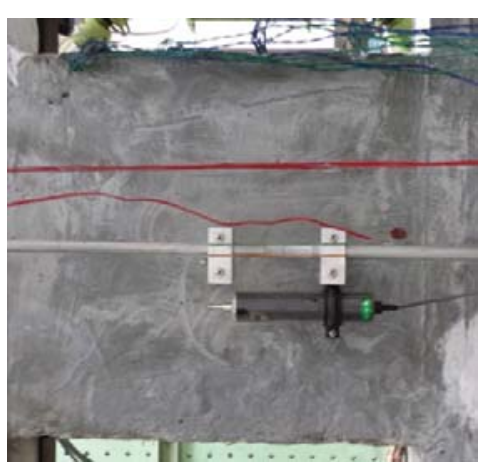

DCB10

Figure 7. Concrete Crack Patterns

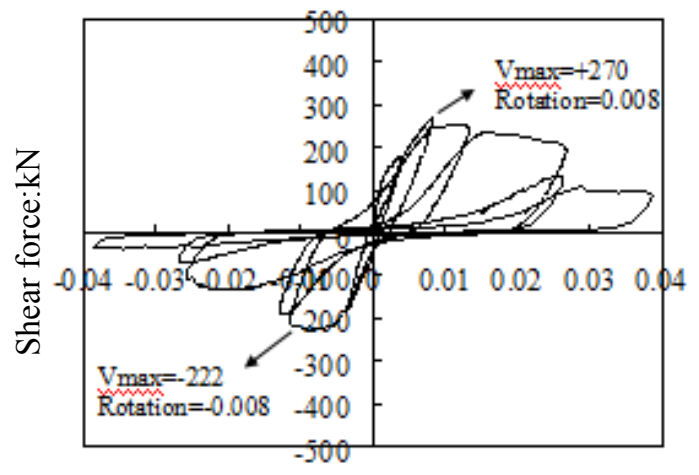

rotation: $\mathrm{rad}$

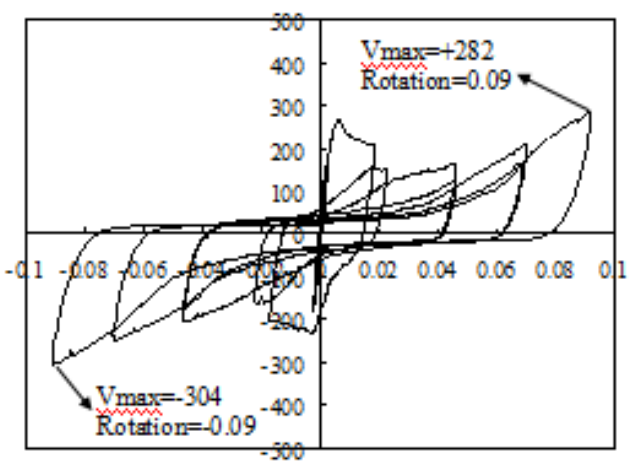

DCB9

DCB8 

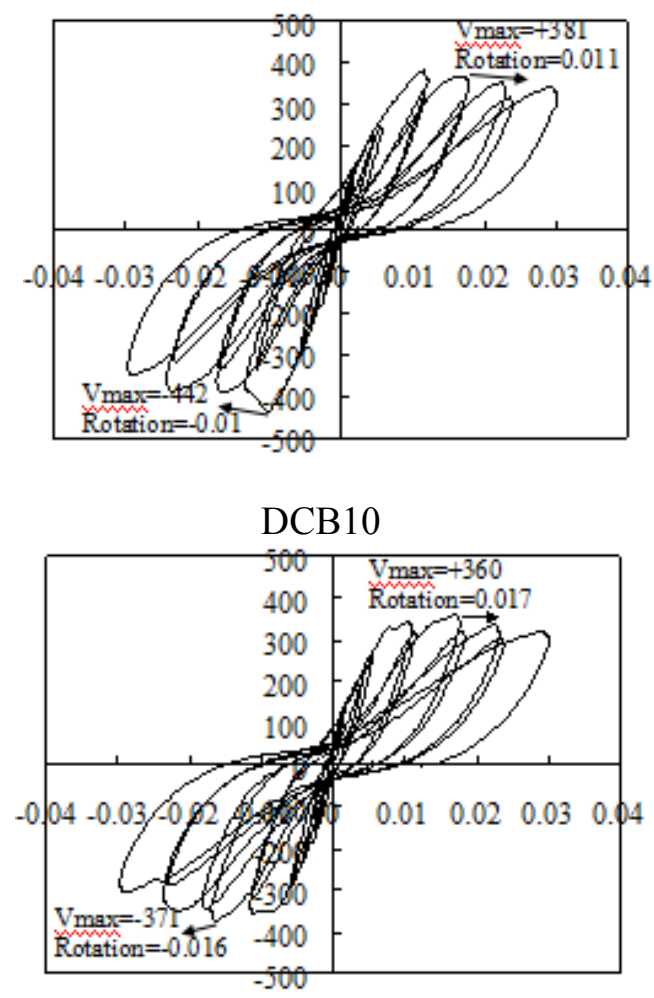

DCB12

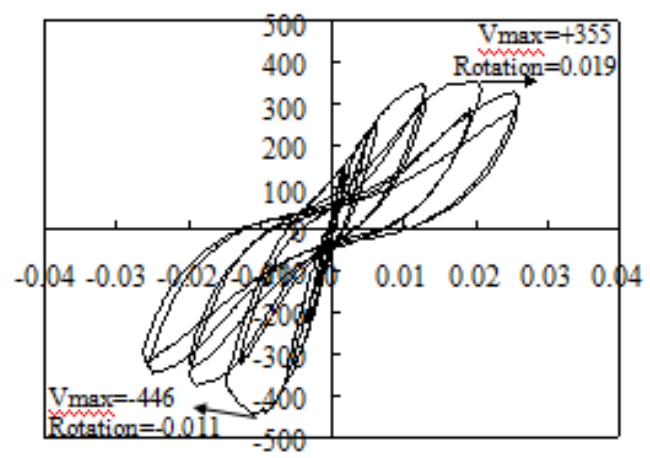

DCB11

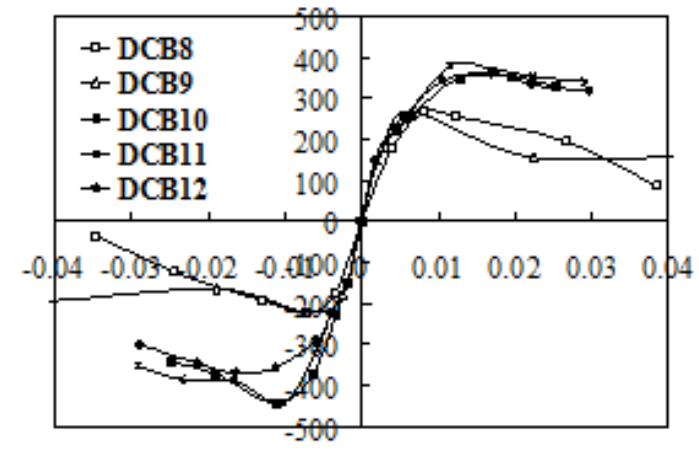

envelope

Figure 8. Load-rotation Curves

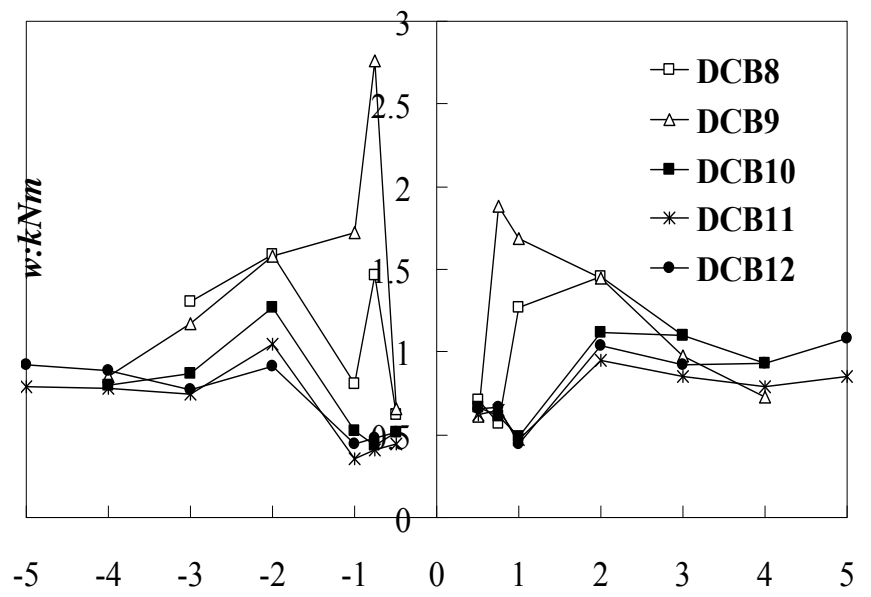

$\mu_{n}$

Figure 9. Variations of Energy Dissipated, with Ductility Level 


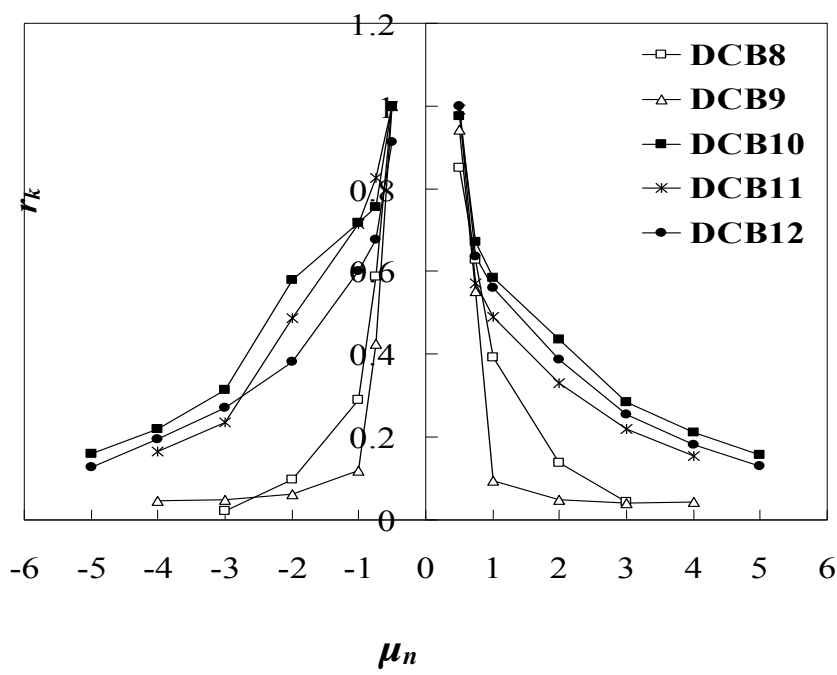

Figure 10. Variations of Stiffness Degradation, with Ductility Level

\subsection{Behaviors of Steel Plates}

The shear and axial strains of the steel plates can be obtained from the rosette strain gauges attached to the plate surfaces. Figure 11 shows the variations of the shear stress rosette 2 at the mid-span of the steel plate. These results reveal that the shear stress in the steel plate has an increasing trend as the chord rotation increases, which means that the steel plate can accommodate more shear forces. For DCB9 with diagonal stiffeners, it can be found from Figure 11 that when the rotation of coupling beam reached to $0.04 \mathrm{rad}$, the shear stress is about $50 \mathrm{Mpa}$. Therefore the steel plate remained in an elastic state. The reason is that, with the adoption of general bolt connections between the steel plate and concrete, the steel plate did not work together with the concrete beam successfully due to the large bolt slippage. Most shear force was resisted by the concrete beam during this loading stage. This resulted in more serious concrete crushing at the beam-wall joints and enhanced the rate of concrete deterioration. It also explains why DCB9 had poor deformability and brittle failure. For DCB10 with diagonal stiffeners and dynamic set connections, the steel plate remained in an elastic state. However, the deformability and ductility were much better than for DCB9. This is due to the fact that, with dynamic set connections, the steel plate and concrete beam worked together effectively. Diagonal stiffeners helped to delay the diagonal crack opening and resisted much of the compressive force at the beam-wall joints region, which resulted in the alleviation of concrete crushing at the beam-wall joints and the expectation that the concrete beam could resist more shear capacity. For DCB11 and DCB12 with horizontal stiffeners, steel yielding occurred suddenly at a rotation of about $0.01 \mathrm{rad}$. At the early loading stage, the concrete beam resisted most of the shear force. Major diagonal cracking occurred at about $0.01 \mathrm{rad}$ and the shear capacity of the concrete beam reduced suddenly. After that, a significant portion of the shear force transferred from the concrete beam to the steel plate, which meant that it yielded and entered into a plastic state. With the rotation increased, for DCB11 with two horizontal stiffeners, due to the larger stiffness of steel plate, more shear force could be resisted. On the other hand, due to elongation of the steel plate with large axial stiffness, more compressive force was applied to the concrete beam which resulted in earlier concrete crushing. This can explain why DCB11 has higher strength but poorer deformability and ductility. Although DCB12 with one horizontal stiffener has lower strength than DCB11, due to the lesser axial stiffness of steel plate, it demonstrates better deformability and ductility. 


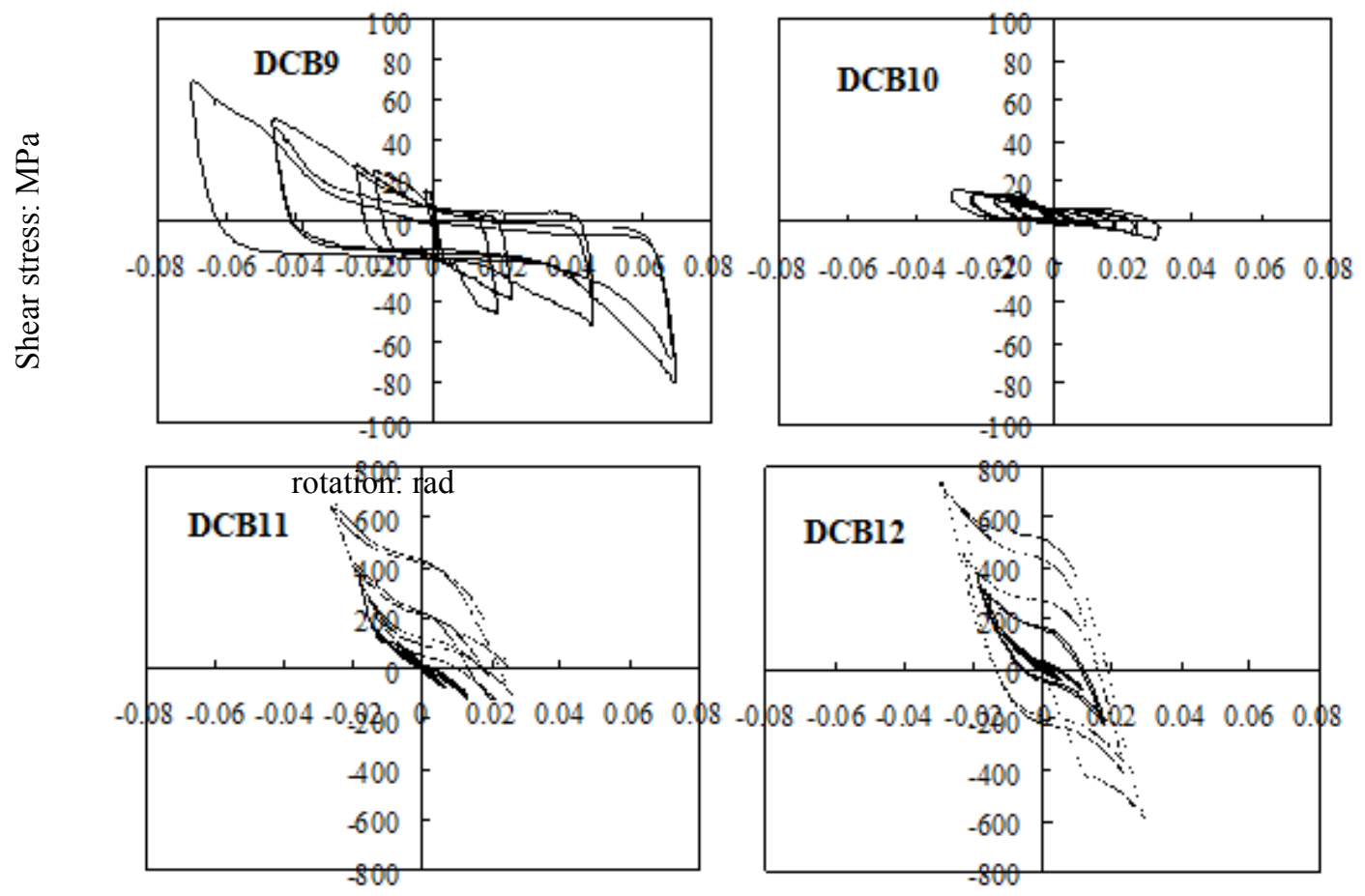

Figure 11. Shear Stress at the Point (Rosette 2) of the Steel Plates

\subsection{Slips of Bolt Groups}

The composite action of coupling beams and a bolted steel plate was accomplished by anchor bolts which must slip under the interfaces of the shear forces. Using the LVDT arrangement (L6-L8), as shown in Figure 6, the average rotational movements at the center of the anchor bolt groups were found.

The rotations determined from the LVDT readings in the longitudinal directions were defined as the 'longitudinal rotation'._The value of longitudinal rotation is divided the deference between L6 and L8 by the distance between them. As shown in Figure 12, the longitudinal rotation of DCB9, which had general bolt connections, is much higher than that of other specimens due to the significant slippage between the concrete and bolt connection. While for DCB10 to DCB12, which had dynamic set bolt connections, the rotation of the bolt group increased almost linearly with the increase in chord rotation, the maximum longitudinal rotation was lower than $0.01 \mathrm{rad}$. This demonstrates that the bolt groups were strong enough and able to behave elastically, while the concrete beams underwent inelastic deformation. 

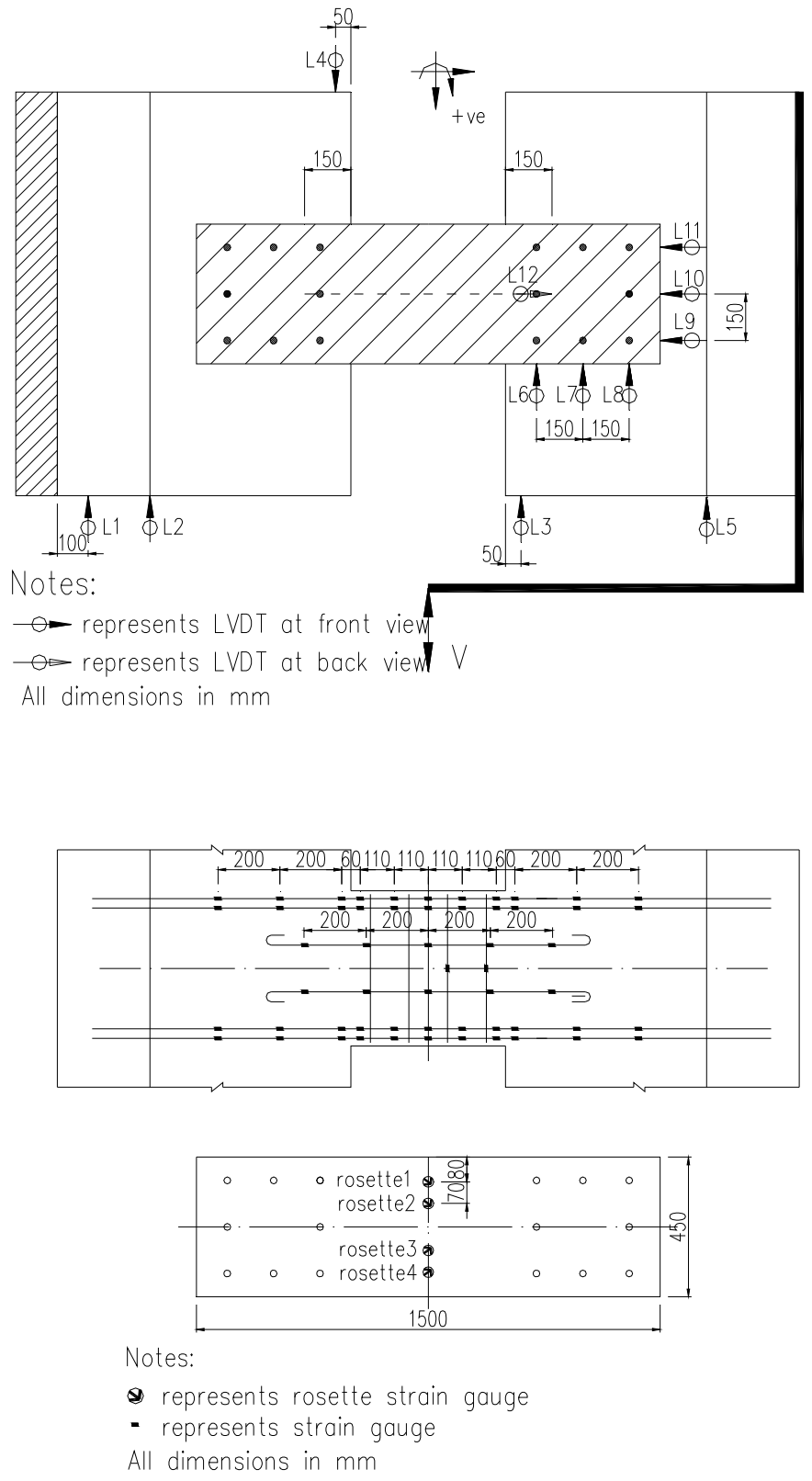

Figure 6. Instrumentation: (a) LVDT Arrangement; (b) Strain Gauge Arrangement 

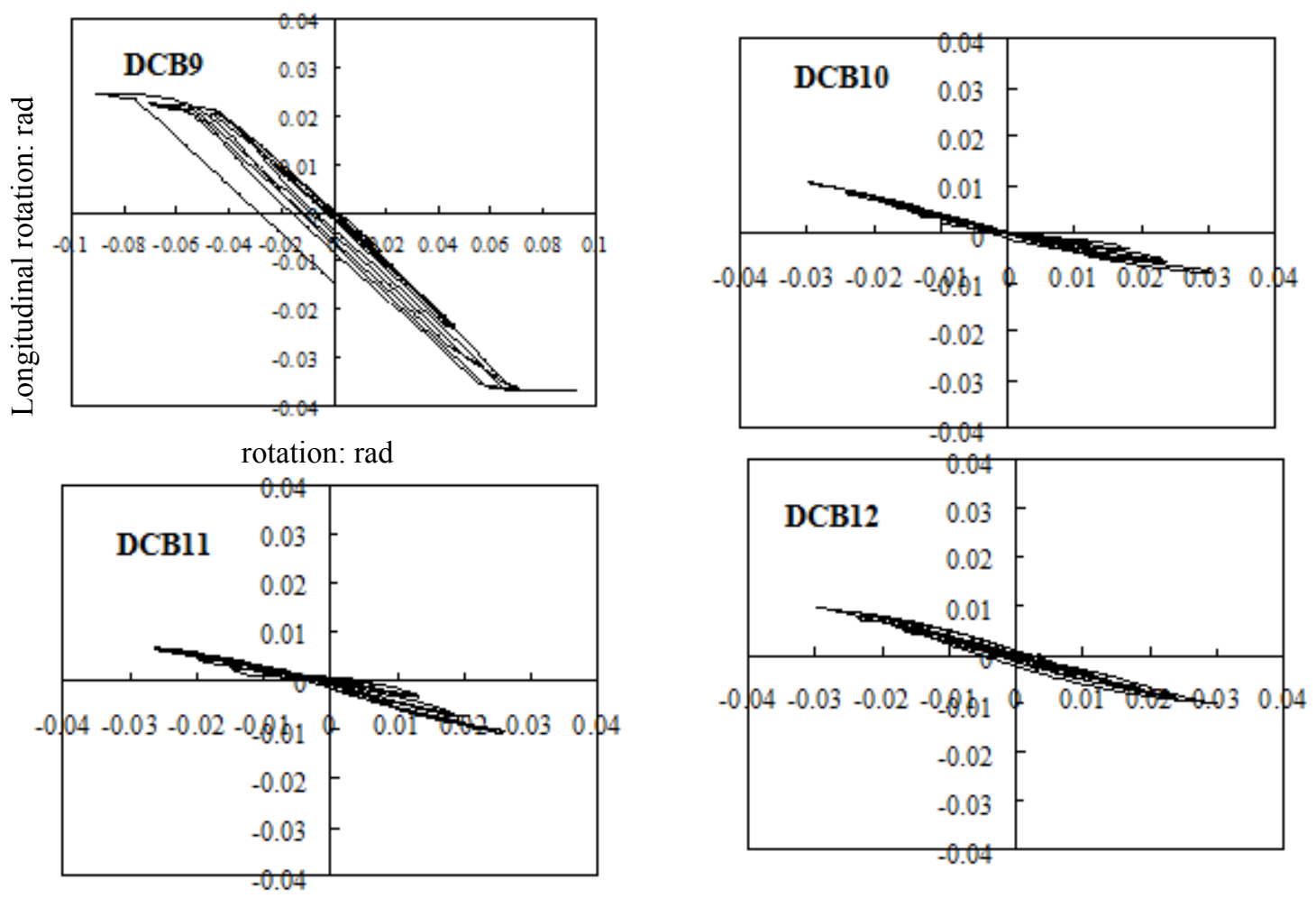

Figure 12. Longitudinal Rotation of Bolt Group

\section{CONCLUSIONS}

Experimental study was conducted on laterally restrained steel plate with stiffeners for the seismic retrofitting of concrete coupling beams. The main findings of this study are summarized as follows:

1. The use of laterally restrained steel plate with stiffeners for the seismic retrofitting of concrete deep coupling beams has demonstrated effectiveness in increasing deformability and energy dissipation while reducing strength and stiffness degradation. Also, the retrofitted beams failed in a less brittle manner.

2. The type of bolt connections used is found to have significant effects on the performances of the retrofitted coupling beams. Dynamic set bolt connections with adhesive to fill in the gap between the concrete and bolt can alleviate bolt slippage and make the retrofitted coupling beams achieve a desirable seismic response. By comparison with the general bolt connections, the shear capacity of the LRSP coupling beam can be increased by $67 \%$ and the ultimate deformation can be increased by $116 \%$ by using dynamic set bolt connections.

3. The stiffener arrangements also have significant effects on the performances of the retrofitted coupling beams. Providing stiffeners can prevent pinching of the hysteresis curves, increase the shear strength and enhance the energy dissipation capacity. On the other hand, too much stiffening would lead to a loss of structural deformability. It is concluded that an optimum amount of diagonal stiffeners should be used to simultaneously achieve desirable strength and deformability. The steel rebars with diameter of twice of the thickness of steel plate are suggested as the diagonal stiffers.

4. The prediction of the shear capacity of retrofitted coupling beams based on the full plastic section assumption without considering the effects of plate buckling and bolt slips would overestimate the true capacity by 10 to $25 \%$. 


\section{ACKNOWLEDGEMENTS}

The work described in this paper has been fully supported by the National Natural Science Foundation (Project No.51208023), Beijing Natural Science Foundation (Project No.8162014) and National Natural Science Foundation (Project No.51408436).

\section{REFERENCES}

[1] Paulay, T., "Coupling Beams of Reinforced Concrete Shear Walls", Journal of the Structural Division, 1971, Vol. 97 (ST3), pp. 843-862.

[2] Mitchell, D., Devall, R.H., Saatcioglu, M., Simpson, R., Tinawi, R. and Tremblay, R., "Damage to Concrete Structures due to the 1994 Northridge Earthquake", Canadian Journal of Civil Engineering, 1995, Vol. 22(2), pp. 361-377.

[3] Wang, Y.Y., "Lessons Learned from the "5.12" Wenchuan Earthquake: Evaluation of Earthquake Performance Objectives and the Importance of Seismic Conceptual Design Principles", Earthquake Engineering and Engineering Vibration, 2008, Vol. 3, pp. 255-262.

[4] Harries, K.A., Cook, W.D. and Mitchell, D., "Seismic Retrofit of Reinforced Concrete Coupling Beams using Steel Plates", ACI SP-160, 1996, Vol. 6, No. 1, pp. 93-114.

[5] Su, R.K.L. and Zhu, Y., "Experimental and Numerical Studies of External Steel Plates Strengthened Reinforcement Concrete Coupling Beams", Engineering Structures, 2005, Vol. 27, No. 10, pp. 1537-1550.

[6] Su, R.K.L. and Cheng, B., "Plate Strengthened Deep Reinforced Concrete Coupling Beams", ICE-Structures and Buildings, 2011, Vol. 164, No. 1, pp. 27-42.

[7] Cheng, B. and Su, R.K.L., "Retrofit of Deep Concrete Coupling Beams by Laterally Restrained Side Plates", Journal of Structural Engineering, 2011, Vol. 137, No. 4, pp.503-512.

[8] Cheng, B. and Su, R.K.L., "Numerical Studies of Deep Concrete Coupling Beams Retrofitted with a Laterally Restrained Steel Plate", Journal of Advances in Structural Engineering, 2011, Vol. 14, No. 5, pp. 903-915.

[9] Lu, Y. and Li, G.Q., "Slim Buckling-restrained Steel Plate Shear Wall and Simplified Model", Advanced Steel Construction, 2012, Vol. 8, No. 3, pp. 282-294.

[10] BSI, CP114, "British Standard Code of Practice, Part 2: The Structural Use of Reinforced Concrete in Buildings", London: The Council for Codes of Practice, British Standards Institution, 1969.

[11] BSI, BS5950, "Structural Use of Steelwork in Building, Part 3: Design in Composite Construction, Section 3.1: Code of Practice for Design of Simple and Continuous Composite Beams", London: British Standards Institution, 1990.

[12] Kwan, A.K.H. and Zhao, Z.Z., "Testing of Coupling Beams with Equal End Rotation Maintained and Local Joint Deformation Allowed", Proceedings of the Institution of Civil Engineers - structures and buildings, 2002, Vol. 152, No. 1, pp. 67-78.

[13] Park, R. "Ductility Evaluation from Laboratory and Analytical Testing", Proceedings of the Ninth World Conference on Earthquake Engineering, Tokyo-Kyoto, Japan, 1988, pp.605-616.

[14] Qian, J.R. and Xu, F.J., "Deformation Decomposition Rule of RC Frame Core Tube Structures”, Building Structure, 2006, Vol.36, No. 12, pp. 33-36. (in Chinese) 